\title{
REVIEW
}

\section{Obesity in childhood and adolescence: evidence based clinical and public health perspectives}

\section{J J Reilly}

Postgrad Med J 2006;82:429-437. doi: 10.1136/pgmj.2005.043836

A global epidemic of paediatric obesity occurred in recent years, and prevalence of obesity is continuing to rise. In the developed world obesity is now the most common disease of childhood and adolescence. Paediatric obesity is not a cosmetic issue, being associated with a significant burden of ill health both for obese children and for adults who were obese as children. Health professionals tend to underestimate the impact of paediatric obesity, and lack the skills, knowledge, and time to treat it effectively. This short review aims to summarise recent systematic reviews on the origins, consequences, prevention, and treatment of paediatric obesity.

Correspondence to: Dr J J Reilly, University Division of Developmental Medicine, University of Glasgow/ Yorkhill Hospitals Glasgow, 1st Floor Tower Block QMH, Yorkhill, Glasgow G3 8SJ, Scotland; ïr2y@clinmed. gla.ac.uk

Submitted

28 November 2005

Accepted 24 January 2006
$\mathrm{A}$ n epidemic of obesity affected children and adolescents across the developed and developing world in recent years. In most of the world, ${ }^{1-11}$ with the notable exceptions of parts of sub-Saharan Africa and the former Soviet Union, obesity is now the most common paediatric disease. Paediatric obesity has overtaken underweight in prevalence in many developing countries..$^{5-7}$ Clinical management and public health strategies to combat the problem of paediatric obesity have been overtaken by the speed and scale of the epidemic. Recent Cochrane reviews on prevention and treatment of paediatric obesity have noted the mismatch between the scale of the problem and our comparatively weak and belated strategies for dealing with it. ${ }^{8}$ Nevertheless, recent systematic provided valuable summaries of best evidence to date and these should help in the development of future clinical and public health responses to the epidemic. The principal aim of this review is to summarise these recent systematic reviews.

\section{DEFINITIONS AND DIAGNOSIS}

Obesity is an excess of body fat: a level of body fat that is harmful. This "definition" is expressed in terms of body fat content, but in clinical practice and epidemiology body fat content can rarely be measured with acceptable precision and accuracy, ${ }^{10-13}$ so simpler alternative definitions are required. There is a good deal of evidence that subjective assessment of obesity is inadequate, and that of the objective approaches the body mass index (BMI; weight in $\mathrm{kg}$ divided by height ${ }^{2}$ in $\mathrm{m}^{2}$ ) is the best available option. ${ }^{10-14}$ The basis for a definition (in epidemiology) or diagnosis (in clinical practice) is therefore the reviews and critical appraisal exercises have
BMI, but as the BMI changes with age and differs between the sexes, it must be interpreted using centile charts that describe population reference data (figs 1 and 2), or by calculation of a standard deviation or ( $\mathrm{Z}$ score or SD score) relative to population reference data. ${ }^{10-15}$

Children and adolescents with a high BMI centile (such as BMI $\geqslant 98$ th centile on the UK 1990 charts) are highly likely to be excessively fat-that is, this obesity definition has high diagnostic specificity (low false positive rate). Such definitions have a moderate sensitivity $^{10}{ }^{11} 15$ - that is, modest false negative rate. Such definitions are also clinically meaningful: they identify children and adolescents at high risk of the comorbidities of obesity. ${ }^{16-18}$

In the UK, the best evidence suggests that overweight and obesity should be defined as BMI $\geqslant 85$ th and $\geqslant 95$ th centiles in research and epidemiology. ${ }^{10}{ }^{14}$ In clinical practice the UK charts only provide 91st and 98th centiles and for pragmatic reasons these should be the basis of our definitions of overweight and obesity respectively. ${ }^{10}{ }^{14} \mathrm{~A}$ number of other countries now have BMI population reference data and centile charts. Where such "national" reference data are available, they should be used to define/ diagnose overweight and obesity. ${ }^{11}$ Where national data are unavailable there is a choice of using either reference data/charts from another nation (such as the USA whose charts are available from the Centers for Disease Control and Prevention) or use of newer "international" definitions of overweight and obesity. ${ }^{12}$ The international approach attempts to link adult BMI based definitions of overweight $(B M I \geqslant 25)$ and obesity $(B M I \geqslant 30)$ to paediatric definitions by providing age and sex specific "equivalent" BMIs in childhood and adolescence. For ease of international comparisons these international definitions are practical. However, four recent studies have compared the diagnostic ability of the international definitions with that of the more traditional national definitions based on national BMI centiles. ${ }^{15}{ }^{19-21}$ In all four cases diagnostic ability of the national approach was greatly superior, and so use of the international approach should be considered with caution. ${ }^{11}{ }^{15} 19-22$

The scale of the obesity epidemic is also heavily dependent on the definition used. Using data from the same survey, prevalence of obesity can vary twofold to sevenfold ${ }^{11}{ }^{19-23}$ depending on whether national reference data or the international approach is taken. Further discussion on the merits of national compared with international approaches is beyond the scope of this 
review, but detailed arguments can be found elsewhere. ${ }^{11} 22$

\section{PREVALENCE}

As prevalence of obesity depends heavily on the definition used and on a number of other factors (for example, the age and representativeness of the sample, or survey, the timing of the study or survey, whether or not height and weight are measured or self reported), summarising recent prevalence estimates around the world is problematic. Nevertheless, in almost all countries to date that have reported on prevalence it is continuing to increase, and dramatic increases have been typical, showing rapid environmental and lifestyle changes in recent years (fig 3). For the developed world, estimates from 2000 onward using national definitions ( such as BMI $\geqslant 95$ th centile) suggest that $10 \%-25 \%$ of the paediatric population was obese. ${ }^{192023-32}$ In England in 2003 for example, 28\% of $2-11$ year olds were overweight or obese (BMI $\geqslant 85$ th centile), up from $22 \%$ in 1995, while $14 \%$ were obese (BMI $\geqslant 95$ th centile), up from $10 \%$ in $1995 .{ }^{33}$

In the developing world, prevalence of overweight and obesity has also increased dramatically in recent years. ${ }^{3-7} \mathrm{~A}$ few exceptions have been described, notably in sub-Saharan Africa and much of the former Soviet Union (where extreme economic hardship has limited the epidemic). Using the international definitions at least $10 \%$ of school age children are overweight or obese worldwide, ${ }^{4}$ and this is highest in the Americas (32\%), then Europe $(20 \%)$, and the Middle East $(16 \%)$.

In the developed world prevalence of paediatric obesity is generally as common in boys as girls. The picture with respect to sex differences in prevalence in the developing world is more complex and difficult to predict. ${ }^{4-7}$ In the developed world paediatric obesity is generally more common in children and adolescents from families of lower socioeconomic status, ${ }^{41}$ but the magnitude of these socioeconomic differences in prevalence is quite limited. In the developing world the picture is again more complex: higher socioeconomic status has usually been associated with higher risk of paediatric obesity, although as the epidemic progresses in the developing world lower socioeconomic status may become more of a risk for obesity. ${ }^{4-7}$

In the USA youth prevalence of obesity is much higher in some ethnic minorities than in the general population. ${ }^{2}$ Evidence from outside the USA is limited at present but suggests that some ethnic minority groups may also be at higher risk. Again, reasons for differences are complex and not entirely clear at present.

\section{HAS THE SCALE OF THE OBESITY EPIDEMIC BEEN UNDERESTIMATED?}

Secular trends in BMI may underestimate the scale of the epidemic. Secular trends in fat distribution (as shown by changes in waist circumference) in England have been even more pronounced than secular trends in $\mathrm{BMI}^{34}$ showing a more intra-abdominal or central pattern of fat distribution in modern children. This evidence also suggests that the cardiovascular and metabolic consequences of the epidemic may have been underestimated using trend data obtained from BMI. In addition, in adults the BMI as a definition of obesity suffers from the weakness that it tends to underdiagnose obesity in non-white populations. ${ }^{35}{ }^{36}$ Evidence from paediatric studies is limited at present but it seems probable that prevalence of obesity in South Asian, Chinese, and possibly Hispanic and African children will be underestimated if criteria based on white populations are applied to them without any attempt to take account of these real biological differences between populations. ${ }^{22}$ Certain populations seem to have, for any given BMI, higher body fat content and a more central fat distribution (the pattern of fat distribution most likely to be associated with cardiovascular and metabolic derangements). ${ }^{35}{ }^{36}$ In addition, these same populations may be at higher risk of some of the comorbidities of obesity, notably diabetes.

\section{CONSEQUENCES - WHY DOES PAEDIATRIC OBESITY MATTER?}

A detailed description of the many and varied adverse consequences of paediatric obesity would be beyond the scope of this review. A recent systematic review of evidence from the developed world ${ }^{16}$ concluded that paediatric obesity was an important health burden in childhood/adolescence and in adulthood. Box 1 gives a summary of the principal health and other adverse effects. In the developed world the most widespread adverse effects in childhood are probably psychosocial. ${ }^{18}$ From a public health perspective the important concern is the impact of child and adolescent obesity on cardiovascular and metabolic health. ${ }^{16-18}$ It is becoming increasingly clear that the obesity epidemic is likely to herald an important public health burden in future from diabetes and cardiovascular disease, ${ }^{16-18}$ and evidence on its economic impact is also emerging. ${ }^{37} 38$ In developing countries the combination of fetal undernutrition followed by neonatal/ infant overnutrition seems to be particularly likely to be associated with later obesity and metabolic/ cardiovascular morbidity. ${ }^{39} 40$

\section{PERCEPTIONS OF OBESITY AMONG HEALTH PROFESSIONALS AND FAMILIES}

Despite the large body of high quality evidence that paediatric obesity does matter in both the short and long term, there is also a great deal of evidence, summarised by Baur, ${ }^{41}$ that it is not perceived as being clinically important by many health professionals, by patients, and by their families (parents). In addition, among those families who are concerned about obesity in their children, the failure of health professionals to treat obesity seriously is probably a common cause of tension..$^{42}$ There is commonly a large gap between the hard evidence and public perceptions of paediatric obesity. Bridging this gap is likely to be necessary if clinical management is to be effective, and if clinical and public health responses to the epidemic are going to succeed. This will require greater efforts in medical education, and education of the wider population as to the impact of paediatric obesity.

\section{CAUSES OF THE PAEDIATRIC OBESITY EPIDEMIC}

In its simplest terms obesity is caused by a chronic positive energy balance-that is, an excess of energy (food) input over output. The magnitude or rate of this energy imbalance can be surprisingly small $(<100 \mathrm{kcal} /$ day in many cases), but must be sustained for a long period for a non-obese child to become obese. Researchers have made a number of attempts to test whether obesity is caused by low energy expenditure (low physical activity) or high energy intake. Most of these attempts at physiological explanations for the epidemic of paediatric obesity have been inconclusive, for several reasons. "Pre-obese" people are not readily identifiable, yet are crucial to understanding the development of obesity. The small degree of daily energy imbalance required to produce obesity may preclude identification of abnormalities in either energy intake or energy expenditure that cause susceptibility to obesity, because of the limited accuracy and precision of measurement of these variables. ${ }^{43}{ }^{44}$ Measurement of dietary energy intake in particular is imprecise and prone to biases, particularly in older children and adolescents where substantial underreporting of energy (food) intake is common. ${ }^{43}{ }^{44}$ Measurement of total energy expenditure with the doubly labelled water method is accurate and precise. ${ }^{43}$ 


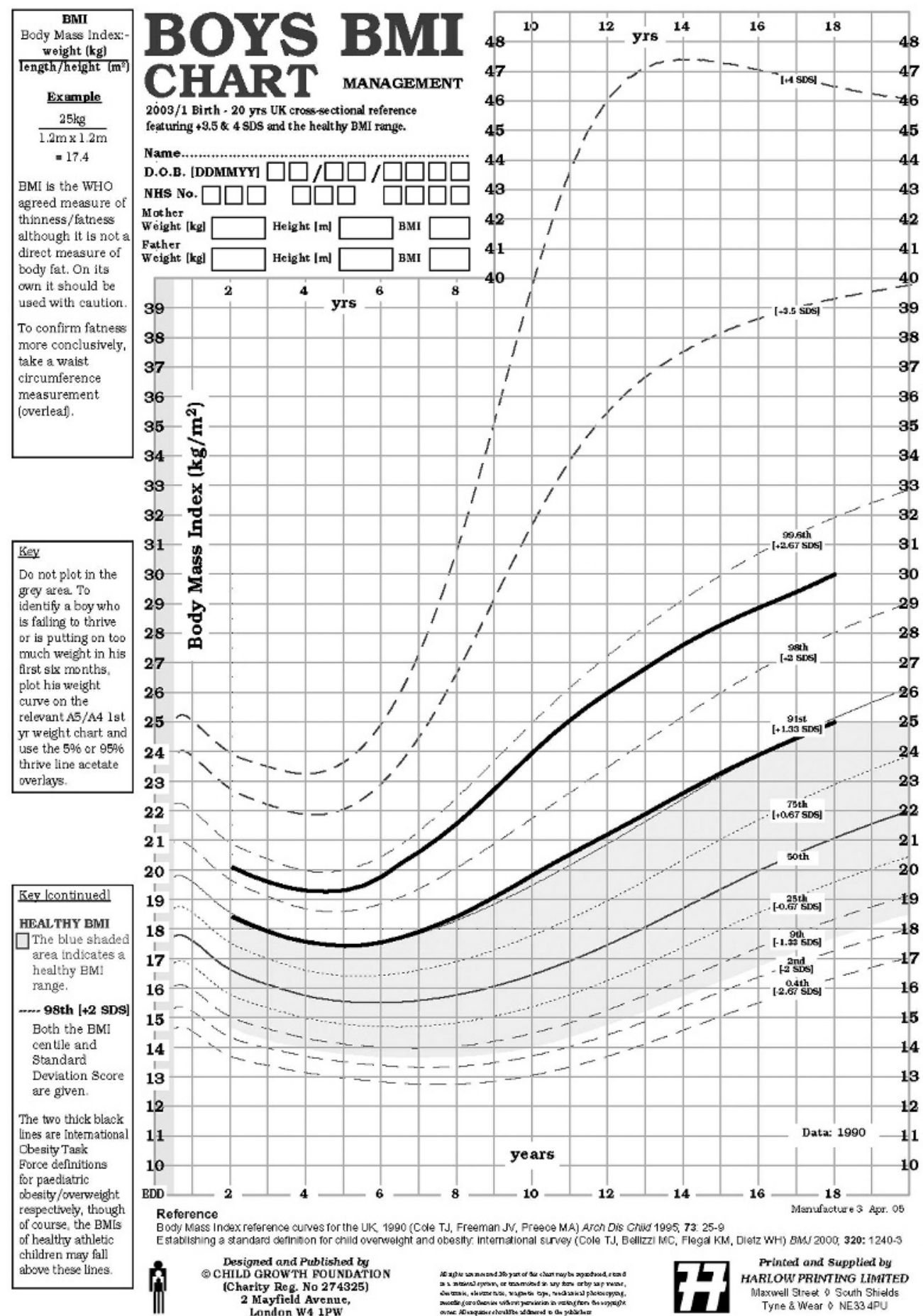

Kev: $\%=$ pereentile
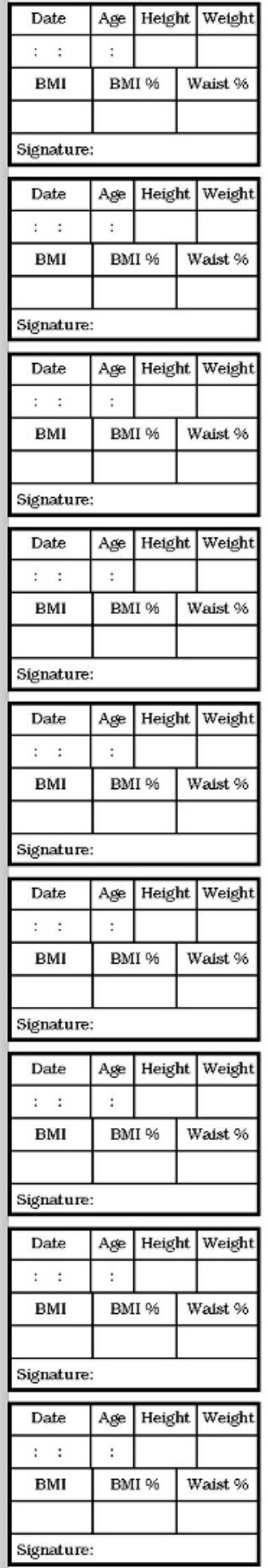

Figure 1 Body mass index centile charts for UK boys, for diagnosis and monitoring of overweight and obesity. (Available from Child Growth Foundation, 2 Mayfield Avenue, London W4 IPW; or from Harlow Printing (http://www.harlowprinting.co.uk).

However, it is also expensive, and the availability of the isotope ${ }^{18} \mathrm{O}$ necessary for doubly labelled water measurements has been limited. Studies to date that have tested the hypothesis that a low total energy expenditure predisposes children and adolescents to obesity or excess fat gain have therefore been few in number, rather small, and inconclusive. ${ }^{11}$

It is increasingly being appreciated that the paradigm of identifying an energy imbalance (in intake expenditure or both) as a "cause" of obesity might be limited. ${ }^{43}{ }^{45}$ The underlying causes of energy imbalance-that is, behaviours or risk factors, may not only be more readily measurable than energy intake and expenditure, but may also be more useful in that they represent possible behavioural targets for any future preventive interventions. ${ }^{45}$

One historical difficulty with this alternative-more epidemiological-approach to studying the causes of obesity has been that systematic reviews have reported that older epidemiological studies of "risk factors" for childhood and adolescent obesity were usually flawed. ${ }^{46}$ Many of these older 


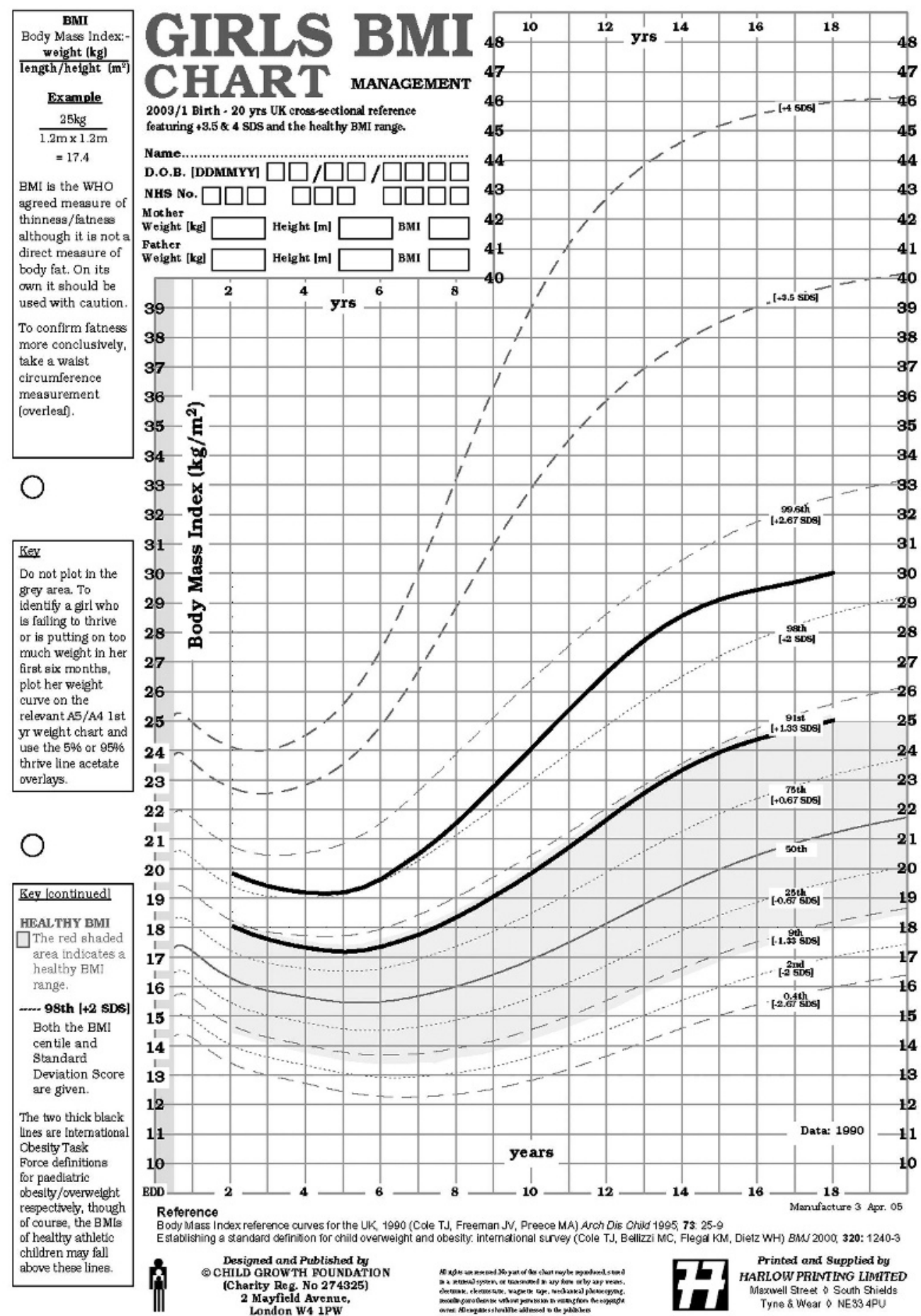

Kcz: $\%=$ pereentile

\begin{tabular}{|c|c|c|c|}
\hline Date & Age & Heigh & \begin{tabular}{l|l|} 
it & Weigh
\end{tabular} \\
\hline : : & : & & \\
\hline BMI & \multicolumn{2}{|c|}{ BMI \% } & Waist $\%$ \\
\hline \multicolumn{4}{|c|}{ Signature: } \\
\hline Date & Agge & Hetgh & ht Weight \\
\hline : : & : & & \\
\hline BMI & \multicolumn{2}{|c|}{ BMI \% } & Waist $\%$ \\
\hline & & & \\
\hline ignat & & & \\
\hline
\end{tabular}

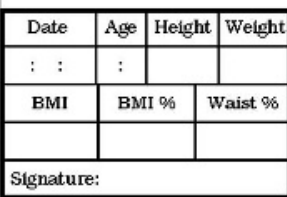

\begin{tabular}{|l|l|l|l|}
\hline Date & Agge & Height & Weight \\
\hline
\end{tabular}

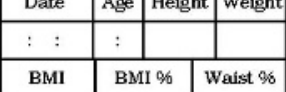

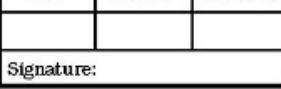

\begin{tabular}{|c|c|c|c|}
\hline Date & Age & Height & Weight \\
\hline$\vdots$ & $:$ & \\
\hline
\end{tabular}

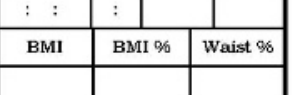

Signature:

\begin{tabular}{|c|c|c|c|}
\hline Date & Age & Height & Welght \\
\hline
\end{tabular}

\begin{tabular}{|c|c|c|c|}
\hline$::$ & $:$ & & \\
\hline BMI & BMI \% & Waist \% \\
\hline & & \\
\hline \multicolumn{3}{|l|}{ Signature: } \\
\hline
\end{tabular}

\begin{tabular}{|l|l|l|l|}
\hline Date & Ade & Height & Weight \\
\hline
\end{tabular}

\begin{tabular}{|c|c|c|c|}
\hline Date & Age & Height & Weight \\
\hline$::$ & $:$ & \multicolumn{3}{|c|}{} & \\
\hline BMI & \multicolumn{2}{|l|}{ BMI \% } & Waist $\%$ \\
\hline & & & \\
\hline & & & \\
\hline \multicolumn{3}{|l}{ Signature: } \\
\hline
\end{tabular}

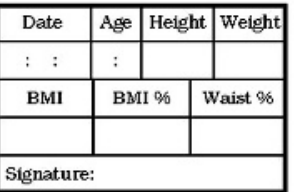

\begin{tabular}{|c|c|c|c|}
\hline Date & Age & Height & Weight \\
\hline$::$ & $:$ & & \\
\hline BMI & BMI $\%$ & Walst $\%$ \\
\hline & & \\
\hline \multicolumn{4}{|l}{} \\
\hline \multicolumn{3}{|l|}{ Signature: } \\
\hline
\end{tabular}

Figure 2 Body mass index centile charts for UK girls, for diagnosis and monitoring of overweight and obesity. (Available from Child Growth Foundation, 2 Mayfield Avenue, London W4 IPW; or from Harlow Printing (http://www.harlowprinting.co.uk).

epidemiological studies were underpowered and had serious limitations in design (many cross sectional studies that used simple univariable analysis). More recent epidemiological studies have been more likely to identify causes of obesity because they have been larger and have adopted longitudinal study designs with multivariable analysis (for example, to control for the confounding effects of socioeconomic status). ${ }^{11} 47$ These recent studies have identified a surprisingly large number of potential risk factors for the development of paediatric obesity, reviewed elsewhere. ${ }^{11}$
From these candidate risk factors for obesity we can apply "decision rules" to identify which are the most promising targets for interventions aimed at paediatric obesity prevention. Whitaker ${ }^{48}$ has suggested that candidate behaviours should meet certain criteria before they are selected as the basis of interventions. Firstly, the behaviour(s) targeted should be causally related to the development of maintenance of obesity-this requires reasonable evidence from energy balance studies or epidemiology, combined with biological plausibility. Secondly, the intervention should do 
Box 1 Principal consequences of paediatric obesity*

In childhood and adolescence

- Psychological ill health

- Cardiovascular risk factors

- Asthma

- Chronic inflammation

- Diabetes (probably type I and II)

- Orthopaedic abnormalities

- Liver disease

In adulthood

- Persistence of obesity

- Cardiovascular risk factors

- Adverse socioeconomic outcomes†

- Premature mortality

*From systematic review and critical appraisal. ${ }^{16}$ †Long term social and economic disadvantage pronounced in women, less obvious in men.

no harm. Thirdly, the behaviour(s) to be modified should aid in child health/ development in other ways. Finally, the behavioural targets for prevention should be measurable: if families cannot measure the behaviour then it will be difficult for them to modify it; if the behaviour(s) cannot be measured objectively with sufficiently high accuracy and precision, then evaluation of the true magnitude of behaviour change is problematic. Many previous dietary interventions have probably been flawed by biased self reporting of changes in dietary intake by participants in intervention studies. ${ }^{49}$

Of all the candidate behaviours or risk factors those that are most likely to meet these Whitaker criteria at present are as follows: formula feeding during infancy (breast feeding provides modest protection against later obesity $\left.{ }^{50}{ }^{51}\right)$; consumption of sugar sweetened drinks (energy consumed in dissolved sugar may not be adequately "recognised" and therefore compensated for by reductions in later energy intake); excessive television viewing (which may either reduce energy expenditure or increase energy intake, or both $^{5253}$ ); low physical activity. ${ }^{54}$ These four behaviours should therefore be regarded as the highest priorities for interventions aimed at prevention of paediatric obesity.

\section{EVIDENCE ON PREVENTIVE INTERVENTIONS}

The evidence on interventions aimed at preventing paediatric obesity has been reviewed systematically by a number of authors ${ }^{810}{ }^{14}$ in recent years. The conclusions of these reviews have been remarkably consistent, in part because of the use of objective methods for literature searching and assessing study quality, and in part because of the limited number of high quality, medium-long term, randomised controlled trials (RCTs). Most RCTs to date have been of limited quality methodologically, short term (often lasting six months or less, which probably biases outcomes in favour of the intervention), and many have tested interventions that are sufficiently complex or specialised that they are unlikely to be generalisable. ${ }^{810}{ }^{14}$ A further concern is that even fewer of the RCTs to date have reported on successful interventions.

To date the only high quality RCT that has tested an intervention that is likely to be successful and generalisable is the Planet Health intervention (box 2) in schools in the Boston area of the USA. ${ }^{52}$ This comparatively large trial (1295 participants, mean age 11 at study entry) used a complex

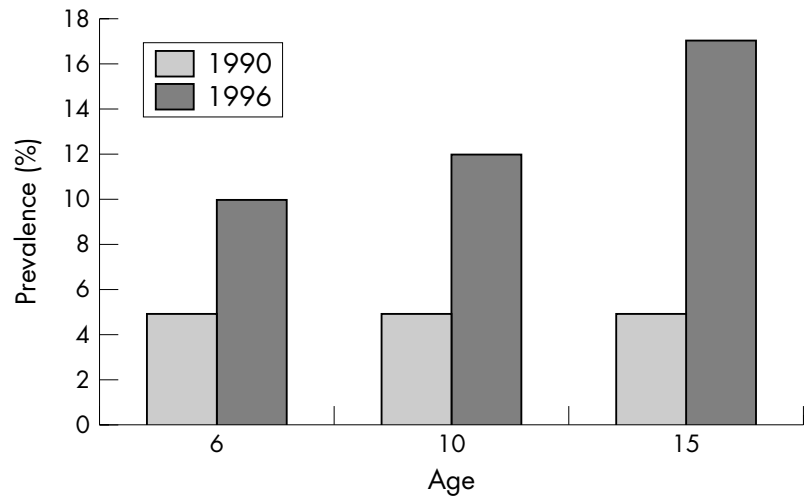

Figure 3 Epidemic of obesity in English children and adolescents during the 1990s (redrawn from Reilly and Dorosty').

intervention over two school years. The intervention consisted of changes to the school curriculum (such as improved physical education), changes to school meal provision, targeted reductions in television viewing, and promotion of walking to/from school. ${ }^{52}$ The intervention was successful (in girls, not in boys) in that risk of becoming obese was significantly reduced (adjusted odds ratio, AOR 0.47, 95\% CI 0.24 to 0.93 ), and there was a significant remission of existing obesity in those who were obese at the start of the trial (AOR 2.16, 95\% CI 1.07 to 4.35). The benefits of the intervention were attributable largely to reductions in television viewing. ${ }^{52}$ Reduced television viewing is one of our most promising strategies for obesity prevention because it is a behaviour that seems to be fairly modifiable, and because reduced time spent watching television probably reduces food intake and/or increases energy expenditure modestly (by increasing physical activity)..$^{52-55}$

The Planet Health trial is a model of obesity prevention intervention, and is particularly promising because its authors have subsequently tackled issues of generalisability and sustainability of the intervention (for example, by producing a handbook for schools that describes how to implement a Planet Health approach into school curriculums). The Planet Health investigators also have promising data on the economic benefits of the intervention. ${ }^{55}$ Nevertheless, the Planet Health approach may not be generalisable to all settings and there is an urgent need to assess the success of other interventions in other populations. Despite the scale and impact of the obesity epidemic there are in fact comparatively few preventive interventions being

\section{Box 2 Planet Health: a school based intervention} for obesity prevention*

The intervention

- Modified school meals

- Increased walking to/from school

- Reduced television viewing

- Changed physical education

\section{Outcomes}

- Reduced obesity risk†

- Curriculum modifications sustainable and cost effective

- Curriculum modifications generalisable

*For further information see Gortmaker et al. ${ }^{52}$ tln girls, not boys. ${ }^{52}$ 
tested in RCT, and most of these have focused on minority groups of adolescents in the USA. ${ }^{56}$ For other population groups in the developed world (for example, young children) there is an even greater dearth of evidence. There are few if any trials aimed at testing preventive interventions underway in the developing world and this is another important research gap that must be tackled urgently.

It has been argued that one of the reasons for the failure of many previous preventive interventions is that by targeting behaviour modification at the "micro" level (that is, individual children, their families, or schools) they are unable to have an impact on the many other influences on weight status that determine the environment at the "macro" level, such as economic or transport policies..$^{57}$ Successful obesity prevention may therefore require a more macro-environmental approach (in addition to or as an alternative to the micro level behavioural changes that have been tested in interventions to date). Taking such an approach would require political/economic action on a scale that has not been attempted by governments yet, to "detoxify" the wider "obesogenic environment". ${ }^{59}$ Some governments may be at least considering actions of this kind. For example, the recent UK Parliament Health Select Committee Inquiry into Obesity ${ }^{38}$ listed a large number of political and economic options for tackling the obesity epidemic that would operate at the macro or societal level.

There is little doubt that governmental and policy issues such as transport and food pricing have had an important impact on the obesity epidemic. The evidence from the developing world has shown that there are a variety of features of societies in economic or nutritional "transition" that commonly underpin dramatic increases in obesity prevalence, and these are discussed in detail elsewhere. ${ }^{60}$ Even in the developed world apparently basic economic and political decisions such as regulations on food pricing may have been important "drivers" of the paediatric obesity epidemic. ${ }^{61}$

\section{PREVENTION OR TREATMENT?}

The adage that "prevention is better than cure" is commonly repeated, but it is worth examining the implications of this statement for childhood obesity prevention and management. Large-and increasing-numbers of obese children and adolescents suffering from the comorbidities of obesity are now seeking treatment across the world. Given the high prevalence and adverse consequences of paediatric obesity it would seem inappropriate not to attempt to treat it. In addition, treatment of those children and adolescents who are already obese is a form of secondary prevention, because successful treatment can prevent adult obesity. In the modern world most preadolescent obese children will remain obese (and so become obese adults), and at least $70 \%$ of obese adolescents will remain obese into adulthood. ${ }^{16} 6263$ This evidence is an argument for greater efforts at both prevention and treatment.

From a public health perspective obesity in itself may be less of a problem than the pervasive nature of some of the health behaviours that cause it. For example, high levels of sedentary behaviour and low levels of habitual physical activity $^{64}$ may be typical of modern children, and these behaviours may be established at an early age, well before school entry. This provides an argument for the promotion of lifestyle modification across the paediatric population, not just in those currently defined as overweight and obese. How this might be achieved is unclear and not without difficulties.

\section{EVIDENCE ON TREATMENT INTERVENTIONS}

The evidence on interventions aimed at treating childhood and adolescent obesity has been reviewed systematically in recent years, and critically appraised, by a number of authors. $^{{ }^{10} 14}$ Many of the weaknesses in the evidence on prevention, listed above, are common to the obesity treatment literature. There have been comparatively few treatment RCTs to date, most have been rated as being of low methodological quality and so prone to bias, most have been comparatively short term (biasing the trial in favour of intervention), and most have tested interventions that are unlikely to be generalisable. ${ }^{9}{ }^{10}{ }^{14}$ However, the literature on treatment has provided some guidance as to how to treat paediatric obesity (box 3), and some "best bets" in treatment are clear from the treatment RCTs and expert committee/ consensus reports. ${ }^{91014}$ The most promising results have been obtained using the pioneering multidisciplinary and intensive treatment approach of Epstein, ${ }^{65}{ }^{66}$ and making this approach more generalisable is a promising strategy for treatment.

Treatment should probably be limited to motivated families, where the child (and preferably the family) perceive the child's obesity as a problem, and seem to be motivated to attempt lifestyle changes. The development of obesity is the result of a long term positive energy balance and treating it requires maintenance of a zero or slightly negative energy balance over a long period (months or years). From a theoretical point of view our treatments should probably continue for longer than is traditionally the case, and should entail more frequent and longer consultations with patients, and these recommendations are backed by some empirical evidence. ${ }^{9}{ }^{1014}$ In children (although possibly not in adolescents), treatment success is most probable if the approach taken is to treat the whole family, rather than just focusing treatment on the obese child. Treatment must entail dietary changes, and the "traffic light" approach of Epstein, ${ }^{65}{ }^{66}$ or modified versions of $i t^{67}$ seem to be practical and promising dietary modification strategies. In brief, this entails children and their families being taught to group foods into three categories: red (high energy density foods, for strictly limited consumption), amber (medium energy density foods, for limited consumption, for example, to mealtimes only), and green (foods of low energy density, to be consumed freely as substitutes for red and amber foods).

Treatment should not focus solely on diet, and must aim to reduce sedentary behaviour (particularly television viewing), and/or increase physical activity. Targeting a reduction in sedentary behaviour, perhaps by introducing limits to television viewing time such as two hours/day (including media use such as computer games and internet use), is one of the most promising elements of treatment. ${ }^{10}{ }^{14}$ As with obesity prevention interventions, reductions in television viewing may be associated with reductions in energy intake and/or with modest increases in physical activity and energy expenditure. Directly promoting increases in physical activity may also be helpful, although it is unclear whether the focus should be on promoting structured aerobic exercise and/or

\section{Box 3 Treatment guidance}

- Treat motivated patients and families

- Modify diet, perhaps using a regimen such as the "traffic light diet"

- Encourage reduced television viewing and media use

- Encourage increased physical activity

- Treat the family, not the child

- Encourage families to self monitor their lifestyle

- Provide more time for consultations with families, and more consultations 
lifestyle physical activity. Obese children and adolescents generally have limited exercise tolerance and may be more amenable to increases in lifestyle physical activity (such as walking to school).

Recent systematic reviews have concluded that several alternative approaches to treatment, which have been the source of great interest, (specific dietary modifications, for example, modifying the glycaemic load of the diet; residential treatment; pharmacotherapy; surgery) are not currently based on high quality evidence. ${ }^{910}{ }^{14}$ Again, there is a need for more high quality and long term RCTs to test the evidence for these approaches. The most recent evidence suggests that many of these newer approaches are promising. For example, glycaemic load modification holds out hope of changing appetite regulation and may eventually be a highly practical dietary strategy; ${ }^{68}$ residential treatments can produce very favourable outcomes at least in the short-medium term (including noticeable improvements in self esteem and psychosocial wellbeing $)^{69}$; recent trials of pharmacotherapy in severely obese adolescents suggest that as an adjunct to lifestyle modification this may be beneficial ${ }^{70}$; surgery is promising for the more severely obese adolescents and/or those with serious comorbidity. ${ }^{71}$ Given this high degree of promise and the scale of the obesity epidemic it is a matter of some urgency that these trials are funded and carried out.

Audits of traditional dietetic and paediatric approaches to treatment of paediatric obesity are generally disappointing. ${ }^{72}{ }^{73}$ For example, in a five year audit of 254 patients at the Sick Children's Hospital in Edinburgh, mostly referred from primary care, $52 \%$ of the patients failed to attend any of the appointments made for them. In the remaining $48 \%$ of patients who attended at least one of the three appointments made, weight maintenance over six months (an aim of management) was achieved in only $22 \%$ (equivalent to about $12 \%$ of all those referred to the clinic). Audit results like these are probably not specific to particular clinic, but reflect a wider failure of treatment. ${ }^{72}{ }^{73}$ They have been interpreted as being unsupportive of any efforts at treatment, but it may be that current treatment approaches are inadequate. Traditional approaches to treatment are probably not sufficiently evidence based, may be insufficiently client centred (see below), and/or insufficiently intense.

A degree of resistance to lifestyle changes must be expected even from patients who seem motivated to change lifestyle. Making and sustaining lifestyle changes is extremely difficult and is usually without any short term benefit to children or their families. ${ }^{74}$ Analogies to obesity treatment can be made to other chronic diseases of childhood that depend on long term lifestyle changes focused on diet, such as cystic fibrosis.

\section{Key points}

- Obesity is now extremely prevalent in children and adolescents across the globe, and prevalence is still increasing.

- Paediatric obesity is best diagnosed using the BMI centile (using centile charts) or standard deviation score.

- Obesity has serious adverse consequences, both for the obese child and for the adult who was obese as a child.

- Most health professionals are unaware of the clinical consequences of paediatric obesity.

- Evidence on the prevention and treatment of paediatric obesity is limited, but useful guidance on best evidence is now widely available.

\section{Key references}

- Summerbell CD, Waters E, Edmunds LD, et al. Interventions for preventing obesity in children. Cochrane Library. Issue 3. Oxford: Update Software, 2005.

- Summerbell CD, Kelly S, Waters E, et al. Interventions for treating obesity in children. Cochrane Library. Issue 3. Oxford: Update Software, 2003.

- Reilly JJ, Wilson M, Summerbell CD, et al. Obesity diagnosis, prevention, and treatment: evidence-based answers to common questions. Arch Dis Child 2002;86:392-5.

- Scottish Intercollegiate Guidelines Network (SIGN). Obesity in children and young people: a national clinical guideline, SIGN 69. http://www.sign.ac.uk

- Barlow SE, Dietz WH. Obesity evaluation and treatment: Expert Committee recommendations. Pediatrics $1998 ; 101-e 29$

Novel "behavioural" approaches to management of cystic fibrosis are more promising in achieving adherence to treatment than more traditional medical /dietary management, ${ }^{74} 75$ and these may provide useful lessons for treatment of other chronic childhood diseases such as obesity. ${ }^{74}$

\section{EVIDENCE ON MANAGEMENT STRATEGIES}

Recent systematic reviews and critical appraisal exercise have concluded that the evidence on approaches to management is limited, consisting largely of expert committee and consensus reports. ${ }^{9}{ }^{10}{ }^{14}$ Nevertheless, these reports provide very useful guidance on basic issues such as: who to treat; when to refer from primary care; what treatment should aim for.

Treatment should be reserved for families with obese patients (defined objectively using the BMI centile or Z score as described above) who seem to be motivated to change their lifestyle.

Referral from primary care should be considered when there is a possibility that there may be an underlying pathological cause of obesity, for example an endocrine cause or genetic syndrome. Such causes of obesity are extremely rare and in the vast majority of paediatric patients the origin of their obesity will lie in their lifestyle ${ }^{73} 7677$ : for these patients referral to secondary care will therefore entail ruling out any underlying pathology. An underlying pathological cause should be suspected in very young (pre-school) children who are severely obese (this may suggest an underlying genetic cause such as monogenic obesity), and in obese children who are short for their age (most obese children are comparatively tall and short stature may suggest a syndromic cause). Referral from primary care will also be necessary where a comorbid condition requires investigation or management (for example, hypertension, dyslipidaemia, metabolic syndrome, sleep apnoea, liver disease, type 2 diabetes).

The principal aim of treatment should be, for most patients, maintenance (not loss) of body weight. The underlying aim of treatment is sustainable lifestyle change: permanent changes to diet, sedentary behaviour, and physical activity. Maintenance of weight is difficult to achieve in the long term but is complemented by the fact that, so long as they are still growing, patients will "grow into their weight" to a degree. For more severely obese patients, and patients where comorbidities may be improved by weight loss (for example, patients with sleep apnoea or type 2 diabetes), 
then modest weight loss (usually no more than $0.5 \mathrm{~kg}$ / month) should be the aim, and a more intensive approach to treatment would be justified. ${ }^{65}$

It is possible that greater clinical and public health efforts should be directed at children and adolescents who are overweight rather than obese (for example, those above the 85 th but below the 95th centile for BMI), but the evidence on treatment strategies for such patients is even more limited. At present most advice is simply to monitor such children as they are probably at high risk of progression to obesity. ${ }^{65}$

\section{CONCLUSIONS}

Paediatric obesity has increased considerably in prevalence across much of the world in recent years and prevalence continues to increase. Obesity in childhood and adolescence is not a cosmetic issue, but has important impacts on short and long term health that are not widely appreciated by patients, their families, or health professionals. The evidence base on strategies for prevention and treatment is limited at present, and is virtually non-existent for the developing world. There is an urgent need for greater research on improved approaches to prevention and treatment across the world. Clinical and public health responses to the epidemic have been overtaken by the speed and scale of the increase in obesity, and the recent emergence of evidence on comorbidities. Large scale societal actions aimed at making the environment less "obesogenic" are probably necessary if the projected increases in prevalence of paediatric obesity are to be avoided. Despite weaknesses in the evidence base, useful guidance on prevention and treatment are now widely available that are based on systematic review and critical appraisal. Some existing treatment and prevention strategies are promising models on which to build future responses to this important crisis in public health.

\section{MULTIPLE CHOICE QUESTIONS (TRUE (T)/FALSE (F); ANSWERS AT THE END OF THE REFERENCES)}

1. Obesity should be diagnosed by
(A) "Eyeballing" the child
(B) Measuring body weight
(C) Comparing weight and height
(D) Calculating BMI and plotting on a centile chart
(E) Measuring waist circumference

2. The following are recognised complications of paediatric obesity
(A) Liver disease
(B) Asthma
(C) Constipation
(D) Insulin resistance
(E) Chronic inflammation

3. Obesity in children in the developed world is

(A) More common in girls than boys.

(B) More common in boys than girls.

(C) More common in families of lower socioeconomic status.

(D) More common in some ethnic minority groups.

(E) More common in children of obese parents.

4. The following behaviours are well established risk factors for childhood obesity

(A) Rapid growth in infancy
(B) Formula feeding in infancy

(C) Television viewing in childhood

(D) Low fruit and vegetable consumption in childhood

(E) High soft drink consumption in childhood

5. Treatment of obese children should usually aim to

(A) Achieve maintenance of body weight

(B) Achieve loss of body weight

(C) Change diet of patients

(D) Change television viewing of patients

(E) Focus solely on the patient, not the family

6. Obese patients should be referred from primary care when

(A) They are severely obese and pre-school age

(B) They are short for their age

(C) They are tall for their age

(D) A comorbid condition is suspected

(E) A pathological cause is suspected

7. What percentage of obese adolescents will become obese adults?

(A) More than $90 \%$

(B) Less than $10 \%$

(C) $30 \%-50 \%$

(D) $70 \%-80 \%$

(E) $\quad 20 \%-30 \%$

Funding: none.

Conflicts of interest: none declared.

\section{REFERENCES}

1 Reilly JJ, Dorosty AR. Epidemic of obesity in UK children. Lancet 1999;354:1874-5.

2 Strauss RS, Pollock HA. Epidemic increase in childhood overweight 1986 1998. JAMA 2001;286:2845-8.

3 Ebbelling CB, Pawlak DB, Ludwig DS. Childhood obesity: public health crisis common sense cure. Lancet 2002;360:473-82.

4 Lobstein T, Baur L, Uauy R. Obesity in children and young people: a crisis in public health. Obes Rev 2004;5(suppl 1):4-85.

5 de Onis M, Blossner M. Prevalence and trends of overweight among preschool children from developing countries. Am J Clin Nutr 2000;72:1032-9.

6 Martorell R, Kettel-khanL, Hughes ML, et al. Overweight and obesity in preschool children from developing countries. Int J Obes 2000;24:959-67.

7 Popkin BM. The nutrition transition and its health implications in lower-income countries. Public Health Nutr 1998;1:5-21.

8 Summerbell CD, Waters E, Edmunds LD, et al. Interventions for preventing obesity in children. Cochrane Library. Issue 3. Oxford: Update Software, 2005.

9 Summerbell CD, Kelly S, Waters E, et al. Interventions for treating obesity in children. Cochrane Library. Issue 3. Oxford: Update Software, 2003.

10 Reilly JJ, Wilson M, Summerbell CD, et al. Obesity diagnosis, prevention, and treatment: evidence-based answers to common questions. Arch Dis Child 2002:86:392-5

11 Reilly JJ. Prevalence and causes of childhood obesity. CAB Reviews: Perspectives in Agriculture, Veterinary Science, Nutrition, and Natural Resources 2006; 1:doi:10.1079/PAVSNNR20051002. http:// www.cabastractsplus.org/cabreviews.

12 Cole TJ, Bellizzi MC, Flegal KM, et al. Establishing a standard definition for child overweight and obesity worldwide. BMJ 2000;320:1240-5.

13 Power C, Lake JK, Cole TJ. Measurement and long-term health risks of child and adolescent fatness. Int J Obes 1997:21:507-16.

14 Scottish Intercollegiate Guidelines Network (SIGN). Obesity in children and young people: a national clinical guideline, SIGN 69. http://www.sign.ac.uk.

15 Reilly JJ, Dorosty AR, Emmett PM, et al. Identification of the obese child: adequacy of the BMI for clinical practice and epidemiology. Int J Obes 2000;24:1623-7.

16 Reilly JJ, Methven E, McDowell SC, et al. Health consequences of obesity: systematic review. Arch Dis Child 2003;88:748-52.

17 Freedman DS, Dietz WH, Srinivasan SR, et al. The relation of overweight to cardiovascular risk factors among children and adolescents. Pediatrics 1999;103:1175-82. 
18 Dietz WH. Health consequences of obesity in youth: childhood predictors of adult disease. Pediatrics 1998;101:518-25.

19 Zimmerman A, Gubeli C, Punterer C, et al. Detection of overweight and obesity in a national sample of 6-12 year old Swiss children. Am J Clin Nutr 2004:79:838-43.

20 Neovius MG, Linne YM, Barkeling BS, et al. Sensitivity and specificity of classification systems for fatness in adolescents. Am J Clin Nutr 2004;80:597-603.

21 Fu WPC, Lee $\mathrm{HC}, \mathrm{Ng} \mathrm{CJ}$, et al. Screening for childhood obesity: international vs. population-specific definitions. Int J Obes 2003;27:11231-6.

22 Reilly JJ. Assessment of childhood obesity: national reference data or international approach? Obes Res 2002;10:838-40.

23 Flegal KM, Ogden CL, Wei R, et al. Prevalence of overweight in US children: comparison of US growth charts from the Centers for Disease Control and Prevention with other reference values for BMI. Am J Clin Nutr 2001;73:1086-93.

24 Rudolf MCJ, Sahota $\mathrm{P}$, Barth $\mathrm{JH}$, et al. Increasing prevalence of obesity in primary school children: cohort study. BMJ 2001;322:1094-5.

25 Ogden CL, Flegal KM, Carroll MD, et al. Prevalence and trends in overweight among US children and adolescents, 1999-2000. JAMA 2002; 288: 1728-32.

26 Bundred P, Kitchiner D, Buchan I. Prevalence of overweight and obese children between 1989-1998. BMJ 2001:322:326-8.

27 Armstrong J, Reilly JJ, Child Health Information Team. The prevalence of under-nutrition and over-nutrition in Scottish children: growth monitoring within the child health surveillance programme. Scott Med J 2003;48:32-7.

28 Tremblay MS, Katzmaryk PT, Willms JD. Temporal trends in overweight and obesity in Canada, 1981-1996. Int J Obes 2002:26:538-43.

29 Kautiinen S, Rimpela A, Vikat A, et al. Secular trends in overweight and obesity among Finnish adolescents, 1977-1999. Int J Obes 2002;26:544-52.

30 Danielzik S, Czerwinski-Mast M, Langnase K, et al. Parental overweight, socioeconomic status, and high birth-weight are the major determinants of obesity in 5-7 year old children. Int J Obes 2004;28:1494-502.

31 Wang $Y$, Wang JQ. A comparison of international references for the assessment of child and adolescent overweight and obesity in different populations. Eur I Clin Nutr 2002;56:973-82.

32 Department of Health. Health survey for England 2003. London: Stationery Office, 2004

33 Popkin BM, Gorden-Larsen P. The nutrition transition: worldwide obesity dynamics and their determinants. Int J Obes 2004:28(suppl 2):s2-9.

34 McCarthy HD, Ellis SM, Cole TJ. Central overweight and obesity in British youth age 11-16 years. BMJ 2003;326:624-28.

35 Deurenberg P, Yap M, Van Staveren WA. Body mass index and percent body fat: a meta analysis among different ethnic groups. Int $J$ Obes 1998:22:1164-71.

36 Deurenberg-Yap M, Schmidt G, Van Staveren WA, et al. The paradox of low body mass index and high body fat percentage among Chinese, Malays, and Indians in Singapore. Int J Obes 2000;24:1011-17.

37 Wang G, Dietz WH. Economic burden of obesity in youths aged 6-17 years, 1979-1999. Pediatrics 2002;109:e81.

38 House of Commons Select Committee into Obesity. Third report of session 2003-2004. London: Stationery Office, 2004.

39 Baird J, Fisher D, Lucas P, et al. Being big or growing fast: systematic review of size and growth in infancy and later obesity. BMJ 2005;doi.10.1136/ bmj.38586.411273.Eo

40 Yajnik CS. The lifecycle effects of nutrition and body size on adult adiposity, diabetes, and cardiovascular disease. Obes Rev 2002;3:217-24.

41 Baur L. Childhood obesity: practically invisible. Int J Obes 2005;29:353-5.

42 Edmunds LD. Parent's perceptions of health professional's responses when seeking help for their overweight children. Fam Pract 2005;22:287-92.

43 Goran MI. Metabolic precursors and effects of obesity in children: a decade of progress. Am J Clin Nutr 2003:73:158-71.

44 livingstone MB, Robson PJ, Wallace JM. Issues in dietary intake assessment of children and adolescents. Br J Nutr 2004;92(suppl 2):s213-22.

45 Wells JC. Is obesity really due to high energy intake or low energy expenditure? Int J Obes 1998;22:139-40

46 Parsons TJ, Power C Summerbell C. Childhood predictors of adult obesity: a systematic review. Int J Obes 1999:23(suppl 1):s1-107.

47 Reilly JJ, Armstrong J, Dorosty AR, et al. Early life risk factors for obesity in childhood: cohort study. BMJ 2005;357:1357-62.

48 Whitaker RC. Obesity prevention in primary care: four behaviors to target. Arch Pediatr Adolesc Med 2003:151:725-7.

49 Byers T. On the hazards of seeing the world through intervention colored glasses. Am J Clin Nutr 2003;78:904-5.
50 Arenz S, Ruckerl R, Koletzko B, et al. Breast-feeding and childhood obesity- a systematic review. Int J Obes 2004;28:1247-56.

51 Owen CG, Martin RM, Whincup PH, et al. Effect of infant feeding on the risk of obesity across the life course: a quantitative review of published evidence. Pediatrics 2005;115:1367-77.

52 Gortmaker SL, Petersen K, Wiecha J, et al. Reducing obesity via a schoolbased interdisciplinary intervention among youth: Planet Health. Arch Pediatr Adolesc Med 1999;151:409-18.

53 Robinson TN. Reducing children's television viewing to prevent obesity: a randomised controlled trial. JAMA 1999;282:1561-7.

54 Reilly JJ. Physical activity and obesity in childhood and adolescence. Lancet 2005;366:268-9.

55 Dietz WH, Gortmaker SL. Preventing obesity in children and adolescents. Ann Rev Publ Health 2001;22:337-53.

56 Reilly JJ. Obesity prevention in childhood and adolescence: review of systematic reviews. In: Cameron N, Norgan NG, Ellison GTH, eds. Childhood obesity - contemporary issues. Boca Raton, FL: CRC Press/Taylor and Francis, 2006:205-22

57 Egger G, Swinburn B. An "ecological" approach to the obesity pandemic. $B M J 1997 ; 315: 477-80$

58 Nestle M, Jacobsen MF. Halting the obesity epidemic: a public health policy approach. Public Health Rep 2000;115:12-24.

59 Livingstone MB, Rennie K. Biobehavioural determinants of energy intake and childhood obesity. In: Cameron N, Norgan NG, Ellison GTH, eds. Childhood obesity - contemporary issues. Boca Raton, FL: CRC Press/Taylor and Francis, 2006:101-18.

60 Popkin BM. Dynamics of the nutrition transition and implications for the developing world. Forum Nutr 2003;56:262-4.

61 Drenowski A, Specter SE. Poverty and obesity: the role of energy density and energy costs. Am J Clin Nutr 2004;79:6-16.

62 Freedman DS, Khan LK, Serdula MK, et al. Racial differences in the tracking of childhood BMI to adulthood. Obes Res 2005;13:928-35

63 Whitaker RC, Wright JA, PCPE MS, et al. Predicting obesity in young adulthood from childhood and parental obesity. NEJM 1997;337:869-73.

64 Reilly JJ, Jackson DM, Montgomery CM, et al. Total energy expenditure and physical activity in young Scottish children: mixed longitudinal study. Lancet 2004:363:211-12.

65 Barlow SE, Dietz WH. Obesity evaluation and treatment: Expert Committee recommendations. Pediatrics 1998; 101:e29.

66 Epstein LH, Myers MD, Raynor HA, et al. Treatment of pediatric obesity Pediatrics 1998;101:554-70.

67 Stewart L, Houghton J, Pearson D, et al. Dietetic management of pediatric overweight: description and development of a practical and evidence-based behavioural approach. J Am Diet Assoc 2005;105:1810-15.

68 Ebbelling CB, Leiding $M M$, Sinclair KB, et al. A reduced glycemic load diet in the treatment of adolescent obesity. Arch Pediatr Adolesc Med 2003;157:773-9.

69 Barton SB, Walker LL, Lambert G, et al. Cognitive change in obese adolescents losing weight. Obes Res 2004;12:313-19.

70 Chanoine JP, Hampl S, Jensen C, et al. Effect of orlistat on weight and body composition in obese adolescents: a randomised controlled trial. JAMA 2005;293:2873-83.

71 Inge TH, Drebs NF, Garcia VF. Bariatric surgery for severely overweight adolescents: concerns and recommendations. Pediatrics 2004;114:217-23.

72 Stewart ML, Deane M, Wilson DC. Failure of routine management of obese children: an audit of dietetic intervention. Arch Dis Child 2004;89/suppl 1):A13-16.

73 Quattrin T, Liu E, Shaw N, et al. Obese children who are referred to the pediatric endocrinologist: characteristics and outcome. Pediatrics 2005:115:348-51.

74 Stark $\amalg$. Can nutrition counselling be more behavioural? Lessons learned from dietary management of cystic fibrosis. Proc Nutr Soc 2003;62:793-9.

75 Lask B. Motivating children and adolescents to improve adherence. J Pediatr 2003:143:430-3.

76 Rudolf MCJ. The obese child. Arch Dis Child Educ Pract 2004;89:ep57-62.

77 Viner R, Nicholls D. Managing obesity in secondary care. Arch Dis Child 2005;90:385-90.

\section{ANSWERS}

1. (A) F, (B) F, (C) F, (D) T, (E) F; 2. (A) T, (B) T, (C) F, (D)

T, (E) T; 3. (A) F, (B) F, (C) T, (D) T, (E) T; 4. (A) T, (B) T, (C)

T, (D) F, (E) T; 5. (A) T, (B) F, (C) T, (D) T, (E) F; 6. (A) T,

(B) T, (C) F, (D) T, (E) T; 7. (A) F, (B) F, (C) F, (D) T, (E) F. 